\title{
Tranexamic acid for the prevention of postpartum hemorrhage: a cost-effectiveness analysis
}

\author{
Wayde Dazelle $^{1}$, Megan Ebner ${ }^{1}$, Jamil Kazma ${ }^{1}$, and Homa Ahmadzia ${ }^{1}$ \\ ${ }^{1}$ The George Washington University School of Medicine and Health Sciences
}

January 19, 2021

\begin{abstract}
Objectives: To estimate the cost-effectiveness of alternative risk-dictated strategies utilizing prophylactic tranexamic acid (TXA) for the prevention of postpartum hemorrhage (PPH).

Study Design: We constructed a microsimulation-based Markov decision-analytic model estimating the cost-effectiveness of three alternative risk-dictated strategies for TXA prophylaxis versus the status quo (no TXA) in a cohort of 3.8 million pregnant women delivering in the United States. Each strategy differentially modified risk-specific hemorrhage probabilities by preliminary estimates of TXA's prophylactic efficacy. Outcome measures included incremental costs, quality-adjusted life-years (QALYs), and adverse maternal outcomes averted. Costs and benefits were considered from the healthcare system and societal perspectives over a lifetime time horizon.
\end{abstract}

Results: All TXA strategies were dominant versus the status quo, implying that they were more effective while also being cost-saving. Providing TXA to all delivering women irrespective of hemorrhage risk produced the most favorable results overall, with estimated cost savings greater than $\$ 670$ million and up to $149,505 \mathrm{PPH}$ cases, 2,933 hysterectomies, and 70 maternal deaths averted, per annual cohort. Threshold analysis suggested that TXA is likely to be cost-saving for health systems at costs below $\$ 184$ per gram.

Conclusions: Our findings suggest that routine prophylaxis with TXA would likely result in substantial cost-savings and reductions in adverse maternal outcomes in this context. The integrity of this conclusion is maintained across all risk-dictated strategies, even when the cost of TXA is significantly higher than what is supported in the literature.

\section{Hosted file}

Dazelle_TXACEA_Figures_AJPvSubmit.pdf available at https://authorea.com/users/383524/ articles/500136-tranexamic-acid-for-the-prevention-of-postpartum-hemorrhage-a-costeffectiveness-analysis

\section{Hosted file}

Dazelle_AJP_TXACEA_vSubmit.pdf available at https://authorea.com/users/383524/articles/ 500136-tranexamic-acid-for-the-prevention-of-postpartum-hemorrhage-a-cost-effectivenessanalysis

\section{Hosted file}

Dazelle_TXACEA_SuppInfo_AJPvSubmit.pdf available at https://authorea.com/users/383524/ articles/500136-tranexamic-acid-for-the-prevention-of-postpartum-hemorrhage-a-costeffectiveness-analysis 